\title{
Design and Construction of Control System for Automatic Voltage Stabilizer
}

\author{
Hnin Hnin Aye \\ Department of Electrical Power Engineering, \\ Technological University, Thanlyin, Myanmar
}

\begin{abstract}
In Myanmar, voltage fluctuation always occurs in electrical supply system. Due to voltage fluctuation, life of electrical equipment consumed electricity is shorted really. To solve this problem, automatic voltage stabilizer is needed for domestic and industries. Both single phase and three phases are available. In this paper intend to known that automatic voltage stabilizer plays efficient role in all type of load i.e. resistive, inductive and capacitive loads. This paper present control circuit for automatic voltage stabilizer provides voltage comparator, relays and servo-controlled motor that compare instantaneous input and output voltage. Automatic voltage stabilizer consists of two unit; measuring unit and regulating unit. In this stabilizer, toroidal type variable autotransformer is used for regulating unit and electronic control circuit is used for sensing unit. Electromechanical or servo control system is used for measuring unit to sense the supply voltage. This electronic control circuit will operate within the fluctuation range from $120 \mathrm{~V}$ to $250 \mathrm{~V}$. The rating of this automatic voltage stabilizer is $7 \mathrm{kVA}$ (single phase) and its frequency range is $50 \mathrm{~Hz}$. The output sensitivity is $\pm 1 \%$. If input voltage is lower than $120 \mathrm{~V}$ or higher than $250 \mathrm{~V}$, the system will be automatic shutdown.
\end{abstract}

Keywords: Voltage stabilizer, LM324, Relays, Controller Design, Performance Test and Results

\section{INTRODUCTION:}

Servo controlled voltage stabilizer is a useful and effective device used to maintain a constant power supply. Voltage fluctuation is a common problem in Myanmar, which can cause damage in electronic devices used in home and in industries. To solve these appliances safe is to use voltage stabilizers. The automatic voltage stabilizers are widely used in industrial application to obtain the stability and good regulation for the sophisticated electrical and electronic equipments such as communication equipments and system, process controller, computer equipment etc [1].

Servo controlled is a closed loop systems for electric motors. The motor used in servo control is usually DC motor used in servo is also possible. The servo system uses a sensor to sense motor position/speed. Servo control has a feedback circuit which changes the drive power going to motor according the control input signals and signal from sensors[2].

There are various types of stabilizers available in market. Both single phase and three phases are available. The rating of this type of stabilizer is quite high and is more economical for high power rating . Based on the change in main voltage, the automatic voltage stabilizers increase or decreases the power supply to rectify the deviation and brings the power supply to normal level. Automatic voltage stabilizer provides a continuous monitoring of output voltage by means of an electronic control circuit that compares the instantaneous output voltage with the set value. Servo voltage stabilizer uses an advance electronic controlled servo controlled motor concept to govern a motorized variable autotransformer. Because of the motor involved, there is a small delay in voltage correction. However, output voltage accuracy is usually $\pm 1 \%$ with input voltage change of $\pm 50 \%$. This stabilization method does not create interference or harmonics in the supply system. 


\section{Servo System Voltage Stabilizer}

In this journal, automatic voltage stabilizer consists of regulating unit and measuring unit. Fig 1 shown below are the block diagram and circuit diagram of the voltage stabilizer connected to an appliance or load. The stabilizers sizes generally with its rating, which is given in $\mathrm{kVA}$.

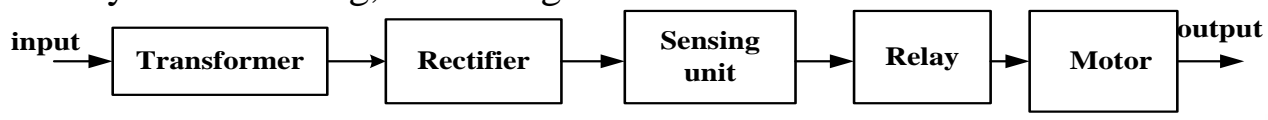

Figure 1. Block diagram of servo controlled voltage stabilizer

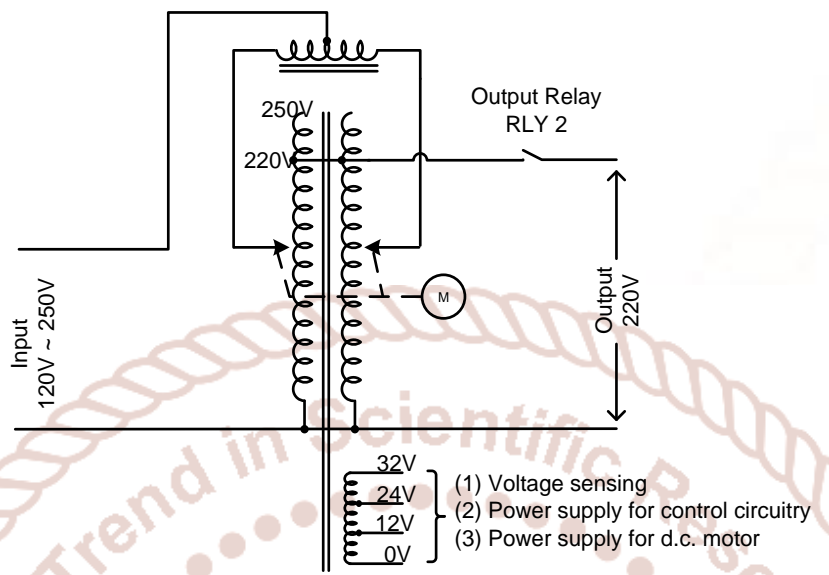

Figure 2.Schematic diagram of automatic voltage stabilizer

The regulating unit consists of toroidal type variable autotransformer. The purpose of the regulating unit is that of acting under the signal from the measuring unit in such a manner as to correct the output voltage of the stabilizer, as near as possible, a constant or predetermined value. Measuring unit includes control circuit. The function of the measuring unit is that of detection a change in the input or output voltage of automatic voltage stabilizer and producing a signal to operate the regulating unit.

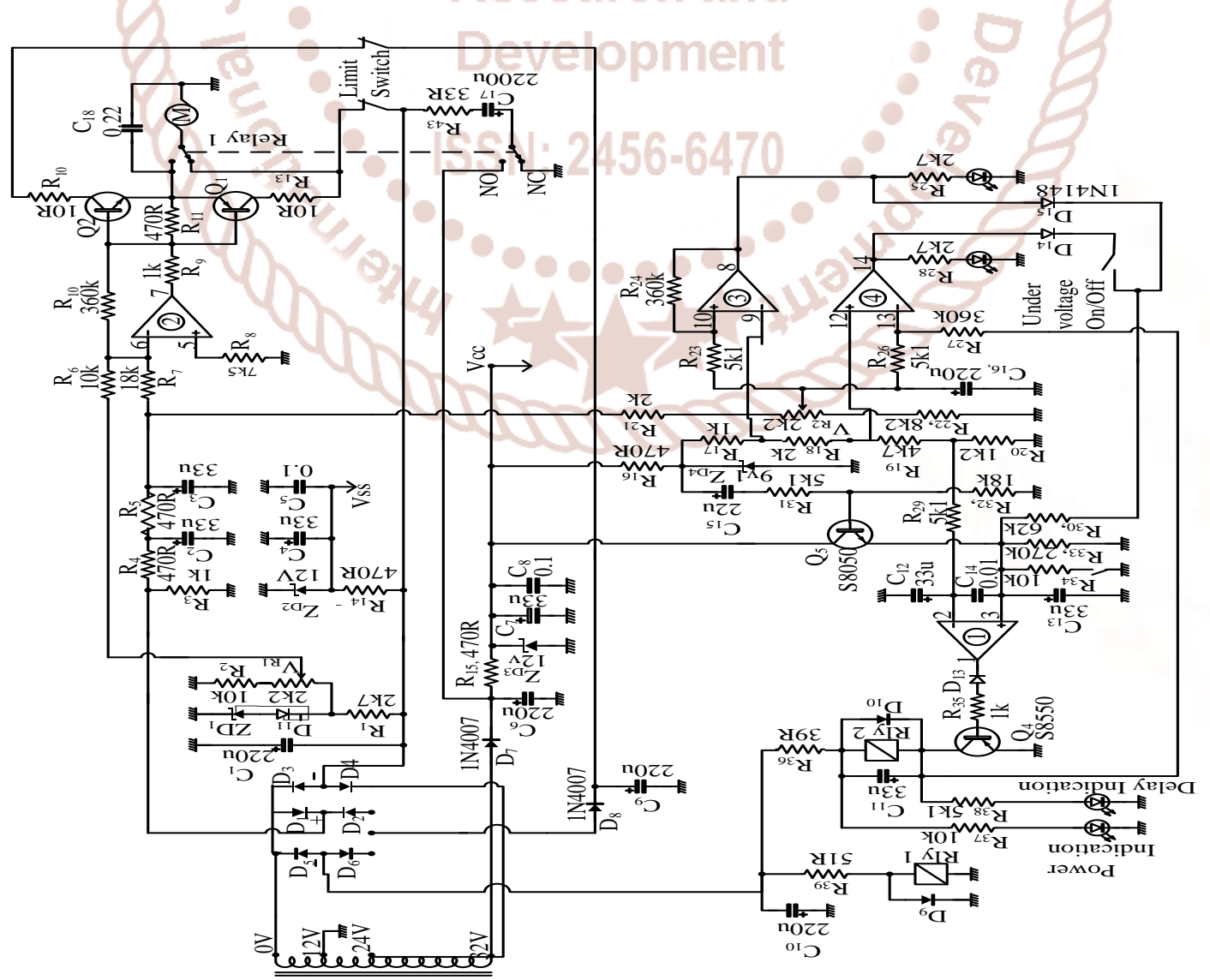

Figure3. Overall Circuit Diagram of AVS 
Overall circuit diagram of control circuit for AVS is shown in fig: 2. Transformer steps down the AC source voltage to $12 \mathrm{~V}$. Then, the transformer output is rectified by bridge rectifier. The rectifier output voltage is filtered by capacitor. In this circuit, LM324 is used as comparator and indicator. The noninverting input $\left(-\mathrm{V}_{\text {in }}\right)$ the op-amp is greater than the inverting input $\left(-\mathrm{V}_{\text {in }}\right)$ the op-amp is ON-state. At normal condition, positive voltage sensing only. If $V_{R 1}$ is adjusted so that when output AC voltage is $220 \mathrm{~V}$, the op-amp output is zero. Op-amp (3) is used for over-voltage condition. It is connected as voltage comparator. When transistor $\mathrm{Q}_{2}$ base receives forward bias and $\mathrm{Q}_{2}$ goes ' $\mathrm{ON}$ ' motor runs in the direction to raise voltage. When transistor $\mathrm{Q}_{1}$ base is forward biased and $\mathrm{Q}_{1}$ goes ' $\mathrm{ON}$ ' motor runs in the other direction to lower voltage. After the present time, opamp output swings positive and release the relay. The control system is automatically shut down when the voltage fluctuation is lower than $120 \mathrm{~V}$ and higher than $250 \mathrm{~V}$.

\section{Design Consideration}

Power supply system is an essential part of each electronic system from simplest to the most complex. Input voltage supply is $220 \mathrm{~V}$ AC supply. Automatic voltage stabilizer control system is based on mainly control circuit.

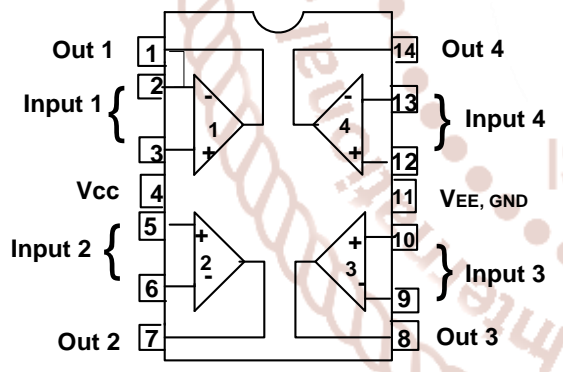

Figure4. Diagram of Pin Function of LM324

In figure 3, LM324 is a 14 pin IC consisting of four independent operational amplifiers (op-amp) compensated in a single package. Op-amp is high gain electronic voltage amplifier with differential input and usually, a single-ended output. The output voltage is many times higher than the voltage difference between input terminals of an op-amp.

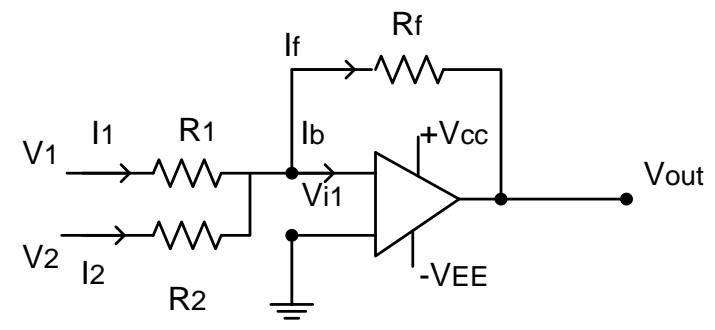

Figure5. Summing amplifier of op-amp
Applying Kirchhoff's Current Law (KCL),

$\mathrm{I}_{1}+\mathrm{I}_{2}=\mathrm{I}_{\mathrm{f}}+\mathrm{I}_{\mathrm{b}}$

$\mathrm{I}_{1}+\mathrm{I}_{2} \approx \mathrm{I}_{\mathrm{f}}$

$\frac{\mathrm{V}_{\mathrm{L}}-\mathrm{V}_{2}}{\mathrm{R}_{\mathrm{1}}}+\frac{\mathrm{V}_{2}-\mathrm{V}_{\mathrm{il}}}{\mathrm{R}_{2}}=\frac{\mathrm{V}_{\mathrm{il}}-\mathrm{V}_{\mathrm{O}}}{\mathrm{R}_{\mathrm{f}}}$

The open loop gain, $A=\frac{V_{0}}{V_{i d}}=\frac{V_{0}}{V_{i 2}-V_{i 1}}$

$\therefore \mathrm{V}_{0}=-\mathrm{R}_{\mathrm{f}}\left[\frac{\mathrm{V}_{1}}{\mathrm{R}_{1}}+\frac{\mathrm{V}_{2}}{\mathrm{R}_{2}}\right]$

\section{RESULTS AND DISCUSSION}

In this section the results obtained from the design calculation of stabilizer controller. There are three conditions by the unstable input supply.

\subsection{Normal Condition}

The parameter of Op-amp 2,

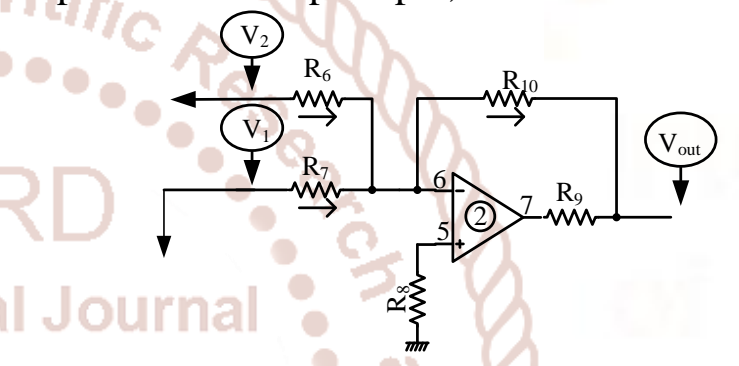

Figure6. Circuit Diagram of Op-amp 2 of LM324N

Op-amp (2) is connected as a summing amplifier.

Applying KCL,

At pin 6 and virtual ground concept

$$
\frac{V_{\text {out }}}{R_{10}}=-\left(\frac{V_{1}}{R_{7}}+\frac{V_{2}}{R_{6}}\right)
$$

$V_{1}$ is positive and represents the sample of output a.c voltage.

$\mathrm{V}_{2}$ is fixed negative voltage: it acts as reference voltage.

Assume, $\mathrm{V}_{1}=9.87 \mathrm{~V}, \mathrm{~V}_{2}=-5.48 \mathrm{~V}$

Apply the KCL,

$\frac{\mathrm{V}_{1}}{\mathrm{R}_{7}}+\frac{\mathrm{V}_{2}}{\mathrm{R}_{6}}=0\left(\because\right.$ In normal condition, $\left.\mathrm{V}_{\text {out }}=0\right)$

$5.48 \mathrm{R}_{7}=9.87 \mathrm{R}_{6}$

If $\mathrm{R}_{6}=10 \mathrm{k} \Omega, \mathrm{R}_{7}=18 \mathrm{k} \Omega$

$\therefore$ The standard of $\mathrm{R}_{6}=10 \mathrm{k} \Omega$ and $\mathrm{R}_{7}=18 \mathrm{k} \Omega$

And then, $\mathrm{I}_{6}=\frac{\mathrm{V}_{2}}{\mathrm{R}_{6}}=-\frac{5.42}{10 \mathrm{k}}=-0.55 \mathrm{~mA}$

$$
\mathrm{I}_{7}=\frac{\mathrm{V}_{1}}{\mathrm{R}_{7}}=\frac{9.87}{18 \mathrm{k}}=0.55 \mathrm{~mA}
$$

If AC output voltage is $1 \%$ change,

$\mathrm{V}_{1}=0.99 \times 9.87=9.77 \mathrm{~V}$

$\frac{V_{\text {out }}}{R_{10}}=-\left(\frac{V_{1}}{R_{7}}+\frac{V_{2}}{R_{6}}\right)$

$\mathrm{V}_{\text {out }}=\left(-\frac{9.77}{18 \mathrm{k}}+\frac{5.48}{10 \mathrm{k}}\right) \mathrm{R}_{10}$ 
$\mathrm{V}_{\text {out }}=5.22 \times 10^{-6} \mathrm{R}_{10}$

Assume motor pick-up voltage $=2 \mathrm{~V}$

$\mathrm{R}_{10}=382 \mathrm{k} \Omega$

$\therefore$ The standard value of $\mathrm{R}_{10}=382 \mathrm{k} \Omega$

In this research, $R_{8}=7.5 \mathrm{k} \Omega$ and $\mathrm{R}_{9}=1 \mathrm{k} \Omega$ are chosen. When $\mathrm{V}_{1}$ falls below normal, inverting input becomes negative and op-amp output swings positive and drives the motor in the direction to increase output voltage. If $\mathrm{V}_{1}$ increase above normal, the process is reverse order.

time delay is calculated by the equation, $V_{c}=V \cdot e^{-\frac{t}{t}}$

$\mathrm{R}=9.642 \mathrm{k} \Omega, \mathrm{C}=33 \mu \mathrm{F}, \mathrm{V}=12 \mathrm{~V}, \mathrm{~V}_{\mathrm{c}}=1.23 \mathrm{~V}$

$-\frac{t}{\tau}=\ln \left(\frac{1.23}{13}\right)$

$\therefore \mathrm{t}=0.7 \mathrm{sec}$

\subsection{Over-Voltage Condition}

The parameter of Op-amp 3,

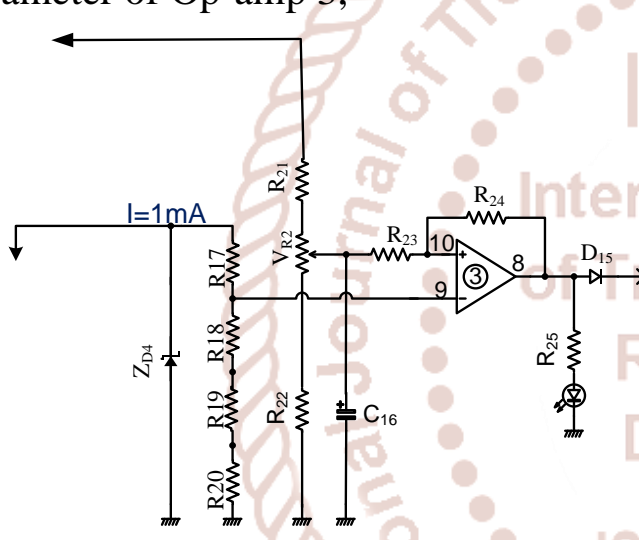

Figure7. Circuit Diagram of Op-amp 3 of LM324N

From normal condition, node voltage $\mathrm{V}=9.87 \mathrm{~V}$

Assume, the non-inverting input (pin 9) $=8.08 \mathrm{~V}$ (fixed voltage)

Assume, $\mathrm{I}=0.8 \mathrm{~mA}$

Non-inverting input (pin10) is fed from voltage sensing supply through voltage divider $\mathrm{R}_{21}, \mathrm{VR}_{2}, \mathrm{R}_{22}$

Apply by KVL,

$\mathrm{IR}_{21}+\mathrm{IV}_{\mathrm{R} 2}+\mathrm{IR}_{22}=9.87 \mathrm{~V}$

$\mathrm{R}_{21}+\mathrm{V}_{\mathrm{R} 2}+\mathrm{R}_{22}=12.34 \mathrm{k} \Omega$

By Ohm's Law,

$\mathrm{V}=\mathrm{IR}$

$\mathrm{R}_{21}=\frac{9.87-8.3}{0.8 \mathrm{~m}}=1.96 \mathrm{k} \Omega$

$\mathrm{V}_{\mathrm{R}_{2}}=\frac{8.3-6.5}{0.8 \mathrm{~m}}=2.2 \mathrm{k} \Omega$

$\mathrm{R}_{21}+\mathrm{V}_{\mathrm{R} 2}+\mathrm{R}_{22}=12.34 \mathrm{k} \Omega$

$\mathrm{R}_{22}=8.2 \Omega$

$\therefore$ The standard value of $\mathrm{R}_{21}=2 \mathrm{k} \Omega, \mathrm{V}_{\mathrm{R} 2}=2.2 \mathrm{k} \Omega$ and $\mathrm{R}_{22}=8.2 \mathrm{k} \Omega$
$\mathrm{V}_{\mathrm{R} 2}$ is adjusted so that at normal condition there is about +7.35 at pin 10 .

At normal condition, op-amp output is negative because $8.08>7.35 \mathrm{~V}$

When output voltage increase to $242 \mathrm{~V}$,

Pin 10 voltage $=8.085 \mathrm{~V}$

Since $8.085 \mathrm{~V}>8.08 \mathrm{~V}$, op-amp output goes positive and drives the relay.

Assume $\mathrm{I}=1 \mathrm{~mA}$ through voltage divider $\mathrm{R}_{17}, \mathrm{R}_{18}, \mathrm{R}_{19}$, $\mathrm{R}_{20}$.

$\mathrm{R}_{17}=1.02 \mathrm{k} \Omega$

Apply by KVL,

$\mathrm{IR}_{18}+\mathrm{IR}_{19}+\mathrm{IR}_{20}=8.08 \mathrm{~V}$

$\mathrm{R}_{18}+\mathrm{R}_{19}+\mathrm{R}_{20}=\frac{8.08}{1 \mathrm{~m}}=8.08 \mathrm{k} \Omega$

$\mathrm{R}_{18}=\frac{8.3-6.5}{1 \mathrm{~m}}=1.8 \mathrm{k} \Omega$

By Ohm's Law,

$\mathrm{R}_{20}=\frac{1.23}{1 \mathrm{~m}}=1.2 \mathrm{k} \Omega$

$\mathrm{R}_{18}+\mathrm{R}_{19}+\mathrm{R}_{20}=8.08 \mathrm{k} \Omega$

$\mathrm{R}_{19}=5.08 \mathrm{k} \Omega$

$\therefore$ The standard value of $\mathrm{R}_{17}=1 \mathrm{k} \Omega, \quad \mathrm{R}_{18}=2 \mathrm{k} \Omega$, $\mathrm{R}_{19}=4.7 \mathrm{k} \Omega$ and $\mathrm{R}_{20}=1.2 \mathrm{k} \Omega$.

In this circuit, $\mathrm{R}_{23}=5.1 \mathrm{k} \Omega$, and $\mathrm{R}_{24}=360 \mathrm{k} \Omega$ is used for prevent short circuit.

Assume, I=5mA for LED lamp

$\mathrm{R}_{25}=\frac{12}{5 \mathrm{~m}}=2.4 \mathrm{k} \Omega$

$\therefore$ The standard value of $\mathrm{R}_{25}=2.7 \mathrm{k} \Omega$

\subsection{Under-Voltage Condition}

The parameter of Op-amp 4,

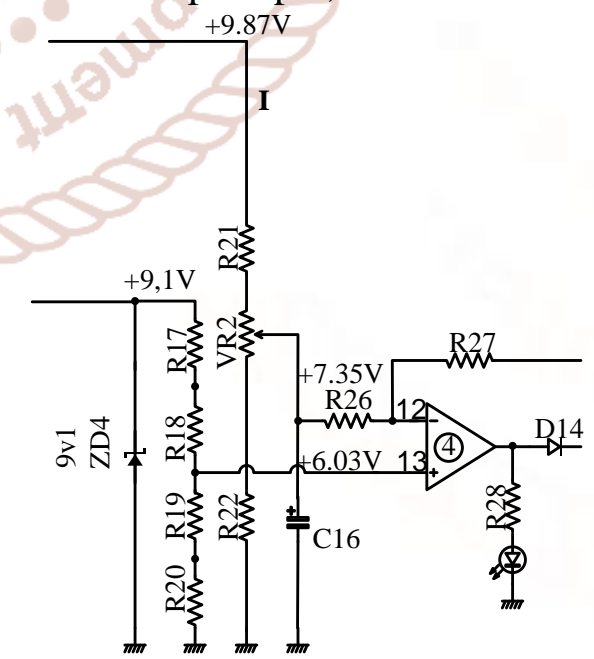

Figure8. Circuit Diagram of Op-amp 4 of LM324N

Under-voltage condition circuit is almost same as over-voltage condition except that op-amp inputs are interchanged. 
International Journal of Trend in Scientific Research and Development (IJTSRD) ISSN: 2456-6470

Reference voltage at non-inverting input is $6.03 \mathrm{~V}$

Assume, fixed voltage $\mathrm{V}=6.03 \mathrm{~V}$ and $\mathrm{I}=1 \mathrm{~mA}$

$\mathrm{R}_{17}=\frac{9.1-8.08}{1 \mathrm{~m}}=1.02 \mathrm{k} \Omega$

$\mathrm{R}_{17}+\mathrm{R}_{18}=3.07 \mathrm{k} \Omega$

$\mathrm{R}_{18}=2.07 \mathrm{k} \Omega$

Apply by KVL,

$\mathrm{IR}_{18}+\mathrm{IR}_{19}+\mathrm{IR}_{20}=8.08 \mathrm{~V}$

$\mathrm{R}_{18}+\mathrm{R}_{19}+\mathrm{R}_{20}=8.08 \mathrm{k} \Omega$

$\mathrm{R}_{19}+\mathrm{R}_{20}=6.03 \mathrm{k} \Omega$

Assume time delay voltage $=1.23 \mathrm{~V}$

By Ohm's Law,

$\mathrm{V}=\mathrm{IR}$

$\mathrm{R}_{20}=\frac{1.23}{1 \mathrm{~m}}=1.23 \mathrm{k} \Omega$

$\therefore \mathrm{R}_{18}+\mathrm{R}_{19}+\mathrm{R}_{20}=8.08 \mathrm{k} \Omega$

$$
\mathrm{R}_{19}=4.78 \mathrm{k} \Omega
$$

$\therefore$ The standard value of $R_{17}=1 \mathrm{k} \Omega, \quad R_{18}=2 \mathrm{k} \Omega$,

$\mathrm{R}_{19}=4.7 \mathrm{k} \Omega$ and $\mathrm{R}_{20}=1.2 \mathrm{k} \Omega$.

In this circuit, $\mathrm{R}_{26}=5.1 \mathrm{k} \Omega$ and $\mathrm{R}_{27}=360 \mathrm{k} \Omega$ is used for prevent short circuit.
Assume, I=5mA for LED lamp

$\mathrm{R}_{28}=\frac{12}{5 \mathrm{~m}}=2.4 \mathrm{k} \Omega$

$\therefore$ The standard value of $\mathrm{R}_{25}=2.7 \mathrm{k} \Omega$

If a.c output voltage falls below $180 \mathrm{~V}$, pin 13 voltage falls below $+6.03 \mathrm{~V}$ and op-amp output goes positive.

When output voltage decreases to $180.4 \mathrm{~V}$,

pin 12 voltage $=\frac{7.35}{220} \times 180.4=6.02 \mathrm{~V}$

Since $6.02<6.03$, op-amp output goes positive and drives the relay.

A variable resistor $V_{R 2}$ is used so that the user can adjust the voltages settings at the desired position. In this case, over-voltage setting $\approx 240 \mathrm{~V}$ and undervoltage setting $\approx 180 \mathrm{~V}$.

time delay is calculated by the equation, $\mathrm{V}_{\mathrm{c}}=\mathrm{V} \cdot \mathrm{e}^{-\frac{\mathrm{t}}{\mathrm{t}}}$

$\mathrm{R}=9.642 \mathrm{k} \Omega, \mathrm{C}=33 \mu \mathrm{F}, \mathrm{V}=12 \mathrm{~V}, \mathrm{~V}_{\mathrm{c}}=1.23 \mathrm{~V}$

$-\frac{t}{\tau}=\ln \left(\frac{1.23}{13}\right)$

$\therefore \mathrm{t}=0.7 \mathrm{sec}$

Table1. Results for low voltage up to $\mathbf{- 4 5 \%}$

\begin{tabular}{|c|c|c|c|c|}
\hline Input voltage & Output voltage & Difference voltage & Clock wise direction & Linear Displacement \\
\hline 210 & 220 & -10 & Cllin1 $13.46^{\circ}$ & 25.841 \\
\hline 200 & 220 & -20 & $26.92^{\circ}$ & 51.683 \\
\hline 190 & 220 & -30 & $40.38^{\circ}$ & 77.524 \\
\hline 180 & 220 & -40 & $53.84^{\circ}$ & 103.365 \\
\hline 170 & 220 & -50 & $67.3^{\circ}$ & 129.207 \\
\hline 160 & 220 & -60 & $80.76^{\circ}$ & 155.048 \\
\hline 150 & 220 & -70 & $94.22^{\circ}$ & 180.89 \\
\hline 140 & 220 & -80 & $107.68^{\circ}$ & 206.731 \\
\hline 130 & 220 & -90 & $121.14^{\circ}$ & 232.572 \\
\hline 120 & 220 & -100 & $134.6^{\circ}$ & 258.413 \\
\hline
\end{tabular}

Table 2. Results for high voltage up to $+13 \%$

\begin{tabular}{|l|l|l|l|l|}
\hline Input voltage & Output voltage & Difference voltage & Anticlockwise direction & Linear displacement
\end{tabular}

\begin{tabular}{|l|l|l|l|l|}
\hline 230 & 220 & +10 & $13.46^{\circ}$ & 25.841 \\
\hline 240 & 220 & +20 & $26.92^{\circ}$ & 51.683 \\
\hline 250 & 220 & +20 & $40.38^{\circ}$ & 77.524 \\
\hline
\end{tabular}

If the supply voltage is lower than $120 \mathrm{~V}$ and more than $250 \mathrm{~V}$, the supply of the motor will be cut out. After that the relay will cut out the supply. So, automatic voltage stabilizer will not produce the power supply without being 220 stable voltage. Fig 11 shows normal condition with digital meter (yellow for input and red for output).

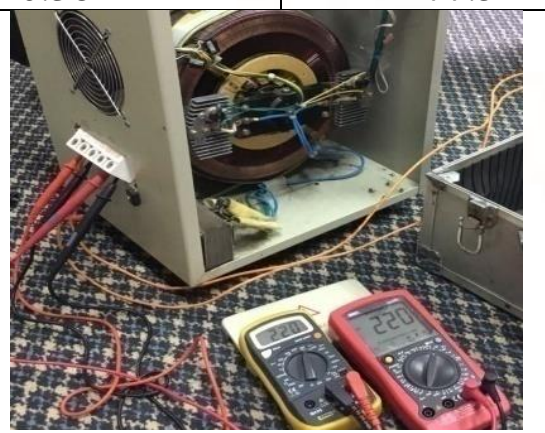

Figure 9.Photo showing 7kVA, Automatic Voltage Stabilizer Control System at Normal Condition 
Fig.10 shows that under voltage condition, the input voltage of the stabilizer is lower than output voltage, the sensing circuit is unbalanced that and the op-amp output is positive. The motor rotates clockwise direction as to increase the stabilizer output voltage to 220V.By testing digital meter (yellow for input and red for output).

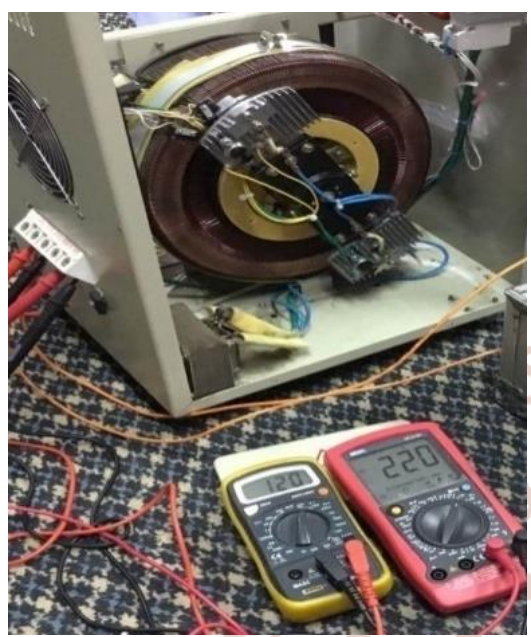

direction. In this research, the input voltage fluctuation can be with stand $120 \mathrm{~V}$ and $250 \mathrm{~V}$ for single-phase $7 \mathrm{kVA}$. The control circuit components are available in local market. So the circuit component can be replaced easily when they are damaged. This automatic voltage stabilizer is very suitable and economical for all electrical equipments. This automatic voltage stabilizer is very convenience and economic for domestics and industries. So, automatic voltage stabilizer having with these conditions will offer the stable output voltage or stable output voltage for all electrical equipments and will improve productivities and reduce downtime.

\section{ACKNOWLEDGMENTS}

The author is deeply grateful to her dissertation superior and co-supervisor. The author also thanks to all teachers at Technological University (Thanlyin) and all who provided her with necessary assistance for this paper. The author wishes to express her guidance to all persons who helped directly or indirectly towards the successful completion of paper. Finally, the author wishes to express her special thanks to her parents for their support and encouragement to attain her destination without any trouble.

Fig.11 shows that over voltage condition, the input voltage of the stabilizer is higher than output voltage, the sensing circuit is unbalanced that and the op-amp output is positive. The motor rotates anti-clockwise direction as to decrease the stabilizer output voltage to $220 \mathrm{~V}$. By testing digital meter (yellow for input and red for output)

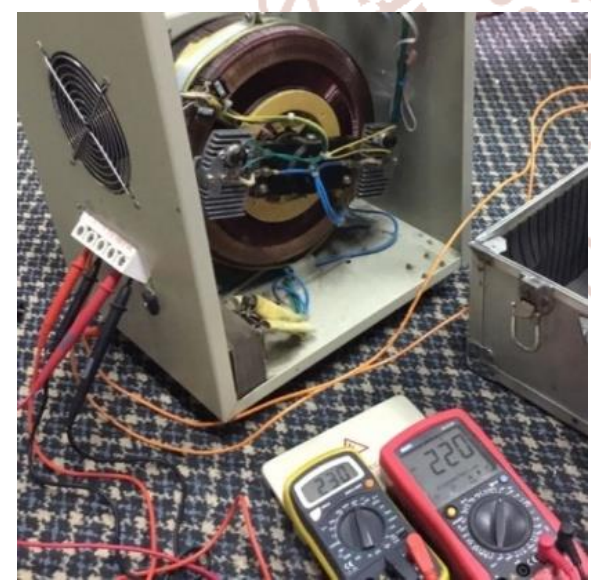

\section{REFERENCES}

1. Servo controlled voltage stabilizer introduction, amjadeeeseminars blogspot, $1^{\text {st }}$ December 2012.

2. P. Eswaran, "Design of fuzzy logic controller for customized servo voltage stabilizer", $2^{\text {nd }}$ International Conference on Electronic and Communication Systems, 26-27 February 2015, pages 103-106.

3. Instruction manual for servo-controlled stabilizer, Servel Electronics Private Limited.

4. McGrana Ghan M. F., Mueller D. R. and Samotyi m. J. (1993), "Voltage Sag in Industrial Systems," IEEE Transactions on Industry Applications, Vol.29, pp.397-403.

5. M. Htay and K. San Win, "Design and Construction of an Automatic Voltage Regulator for Diesel Engine Type Stand-alone Synchrous Generator,” PP.652-658 Stabilizer Control System at over-voltage Condition
Figure 11.Photo showing 7kVA, Automatic Voltage

\section{CONCLUSION}

In this circuit when the input voltage is lower than $220 \mathrm{~V}$, the relay starts energized and the motor rotates the clockwise direction. And then the input voltage is higher than $220 \mathrm{~V}$, the motor rotates the anticlockwise 